\title{
WebCas electronic questionnaire to evaluate health-related behaviors of schoolchildren
}

\author{
Rosimeide Francisco dos Santos Legnani ${ }^{1,3,6,7}$ (1) , Elto Legnani ${ }^{2,3,5,6}$ (1) , Tiago Augusto Andrade ${ }^{5,6}$ (1) , Rafael Vieira \\ Martins $^{6,7}$ (1) , Eva Luziane Denkewicz Gustave ${ }^{1,6}$ (1) , Wagner de Campos ${ }^{4,7}$ (1) \\ ${ }^{1}$ Universidade Estadual de Ponta Grossa, Ponta Grossa, PR, Brasil, ${ }^{2}$ Universidade Tecnológica Federal do Para- \\ ná, Curitiba, PR, Brasil; ' ${ }^{2}$ Universidade Tecnológica Federal do Paraná, Programa de Pos-graduacao em Educa- \\ cao Fisica, Curitiba, PR, Brasil; ${ }^{4}$ Universidade Federal do Paraná, Curitiba, PR, Brasil; ${ }^{5}$ Universidade Tecnológi- \\ ca Federal do Paraná, Programa de Pos-graduacao em Engenharia Biomedica, Curitiba, PR, Brasil; ' ${ }^{\text {Universidade }}$ \\ Tecnológica Federal do Parana, Grupo de Pesquisa em Atividade Física, Esporte e Tecnologia, Curitiba, PR, Bra- \\ sil, ${ }^{7}$ Universidade Federal do Paraná, Centro de Pesquisa em Atividade Fisica e Saude, Curitiba, PR, Brasil.
}

\begin{abstract}
Aims: To present to the scientific community the transposition of the printed version to the electronic version of the WebCas questionnaire. Methods: The transposition of the printed version to the electronic version of the WebCas questionnaire was carried out using the service of a computer programming professional. Through a response interface, the students had access to instructions to respond to the questionnaire. The MySQL 5 method was used to store the information, allowing the generation of reports. To record the responses, students were instructed to click on the chosen option. In case of error, they should choose another option, changing the option chosen previously. The "next" arrow indicated that the individuals being evaluated could change the page. Results: The WebCas questionnaire presented several functionalities related to its presentation and filling out process. In the restricted access to maintenance activities, it is possible to visualize 8 icons: 1 - questionnaire (information regarding the completion and development methodology of the questionnaire); 2 - students (registration information, anthropometric data and student code); 3 - activities (name of the activity, the domain such activity is inserted, intensities and values in MET's); 4 - questions (statement and category of the question); 5 - graphs (showing the results of each question in the bar or pie format graphs); 6 - reports (reports export). Conclusion: The WebCas questionnaire is a technological resource that will assist health researchers in the collection, storage, and preliminary processing of information regarding health-related behaviors in schoolchildren.
\end{abstract}

Keywords: physical activity; transposition; questionnaires; schoolchildren.

\section{Introduction}

Over the last few years, there have been significant changes in people's lifestyle, especially those related to physical activity. In this aspect, the lack of physical exercise, inadequate eating habits, alcohol and cigarette consumption, and insufficient sleeping habits, are the predominant behavioral and biological factors affecting various types of diseases, especially cardiovascular ones ${ }^{1-3}$. The increasing presence of these behavioral factors has aroused the interest of health specialists in the use of new technologies in order to investigate the promotion of healthy habits ${ }^{4}$. While technology can contribute to increased sedentary behavior and high levels of insufficient physical activity, on the other hand, the public health field seeks to support technological resources in order to optimize the diagnosis and the treatment of various diseases ${ }^{5}$. In general, in diagnostic or epidemiological studies, several resources are used, but self-report instruments are the most popular and accessible ones.

From this perspective, printed questionnaires are the tools that can help researchers around the world to obtain relevant information on health aspects of various population groups. Despite the widespread use, printed questionnaires seem to meet the current needs. However, from the productive and resource-saving point of view and, and faster information gathering, it seems prudent to suggest the need to modify the questionnaires application format to more effective and practical models, such as online or electronic questionnaires ${ }^{6,7}$, especially because, the use of printed questionnaires is a common procedure among health researchers.

Recently, several electronic questionnaires have appeared to evaluate health-related behaviors ${ }^{8-10}$. The use of electronic instruments in epidemiological assessments promptly contributes to the reduction of financial costs, especially due to their practicality, saving of material and financial resources, reducing the time spent on their application, and, mainly, by eliminating data entry by researchers ${ }^{11}$.

In this sense, it seems interesting the presence and dissemination of technological devices that help researchers and health professionals to collect data in a more practical, modern, safe, and comprehensive manner, especially in relation to lower cost, contributing to more accurate and comprehensive diagnoses ${ }^{12}$. Therefore, this research aims to present to the scientific community the transposition process from the printed version to the electronic version of the WebCas questionnaire. 


\section{Methods}

The study was approved by the Ethics Committee on Research with Human Beings of the Universidade Federal do Paraná, under Opinion number: 684.147 / 2014, of June 11, 2014. The transposition of the printed version to the electronic version of the WebCas questionnaire was performed using the service of a computer programming professional. In the preparation of the application, the main resources of information technology were used. Table 1 presents the main technological tools employed in the preparation of the WebCas electronic questionnaire.

The WebCas was designed to be viewed in segments on a computer or mobile screen and followed the same structure as its printed version ${ }^{11}$. In each segment, questions related to sleeping hours; the usual practice of physical activity (previous day AF recall); eating frequency; sedentary behavior; sleeping habits; alcohol and cigarette consumption, and socioeconomic status, respectively.

WebCas is hosted on a website that can be accessed at www. legnaniwebcas.com.br (figure 1), which was built for the project "Comportamento Ativo e Saudável (Active and Healthy Behavior) CAS II", which can be accessed through Internet browsers (Explorer, Mozilla, Google Chrome) on personal computers, notebooks and mobile devices (smartphones and tablets). The WebCas electronic questionnaire was designed for academic research purposes, with no charges to the user, and can be accessed by researchers from all over Brazil. To do so, the researcher just has to make a personal registration, as well as the institution object of the research, in this case, the school from which the data will be collected.

To illustrate the questionnaire, colored images referring to the questions were added. After a preliminary study, some difficulties were found regarding the interpretation of the images representing the physical activities performed by the students, especially regarding the characterization of the PA intensities (weak, moderate, and intense). After a study with a focus on groups conducted by Legnani11, in order to assist the students in filling out the remainder of the physical activities performed on the previous day, the illustrative images referring to each question contained in the instrument were inserted.

Students have access to instructions to answer the WebCas questionnaire through an answer completion interface. To store the information regarding the students' answers, a database management system was added using the MySQL 5 method (MYSQL, 2004), enabling the creation of reports that can be exported to spreadsheets in Windows Excel (xls) format.

In the WebCas questionnaire, in order to record their answers, the students are instructed to click on the question chosen, and, in case of error, the students should click on the other option in order to change their answer. Directional keys (arrows) can assist the participants in switching screens by simply clicking on the "next" arrow.

\section{Results}

As an innovation differentiator, the WebCas questionnaire presents several features regarding presentation and completion. In this regard, WebCas has a module restricted to maintenance activities, where you can see 8 icons: (1) questionnaire; (2) students; (3) activities; (4) questions; (5) graphics; (6) reports, (7) settings, and (8) exit.

The first "quiz" icon provides descriptive information, questionnaire filing out instructions, and WebCas development methodology. The second icon, "Students" presents the student code, registration information, and anthropometric data. The third icon "Activities" presents the name of the activity, the domain in which it is inserted, and its intensities (weak, moderate, and strong) and their values in MET's. The fourth icon "Question" presents the statement and the category of the question. The fifth "Graphs" present the results of each question in the bar or pie format graph. The sixth icon "Report" exports the database results to an Excel spreadsheet. The seventh icon "Settings" makes it possible to include or exclude information or updates, domain types from activities and users, and the eighth icon "Exit" leaves the restricted web environment (FIGURE 5). Settingsrelated functionality makes WebCas a dynamic and flexible tool, enabling the inclusion and exclusion of specific research questions.

TABLE 1 - List of technologies used in the preparation of the WebCas electronic questionnaire, and access websites.

\begin{tabular}{|c|c|c|}
\hline Technology & Functionality & Access \\
\hline Web platform "ASP.NET & $\begin{array}{l}\text { Provides services for building professional web applications on the ASP.NET server. Applications can be written in any common } \\
\text { language runtime-compliant language including Visual Basic and C \# }\end{array}$ & (http://www.asp.net/mvc/mvc4) \\
\hline $\begin{array}{l}\text { Models; Views; Controllers (ASP.NET } \\
\text { MVC): }\end{array}$ & $\begin{array}{l}\text { Tool that allows you to develop software, create web applications with three functions. The project is divided into three parts, Mod- } \\
\text { els (M) represent data and business logic; Views (V) create the user interface, and Controllers (C) program the data input logic). }\end{array}$ & (http://www.asp.net/mvc/mvc4) \\
\hline jQuery: & Library rich cross-browser JavaScript library designed to simplify client-side scripts that interact with HTML & http://jquery.com/ \\
\hline Bootstrap: & HTML5 structure and CSS3 framework designed to help you leverage web application and website development & http://getbootstrap.com/ \\
\hline MySQL & Database Management System uses Structured Query Language (SQL). & https://www.mysql.com/ \\
\hline API & Application programming interface (API), which is a set of routines, protocols, and tools for building software applications. & \\
\hline Google Chart & $\begin{array}{l}\text { Google Chart app allows people to create graphs of various styles from some data and embed them in a webpage. Google Chart } \\
\text { creates an image of a graph from data and formatting parameters in a Hypertext request. Transfer Protocol (HTTP). }\end{array}$ & https://developers.google.com/chart/ \\
\hline НTTP & $\begin{array}{l}\text { HTTP is a communication protocol used for distributed and collaborative hypermedia information systems, it is the basis for } \\
\text { data communication on the World Wide Web (internet). }\end{array}$ & \\
\hline
\end{tabular}




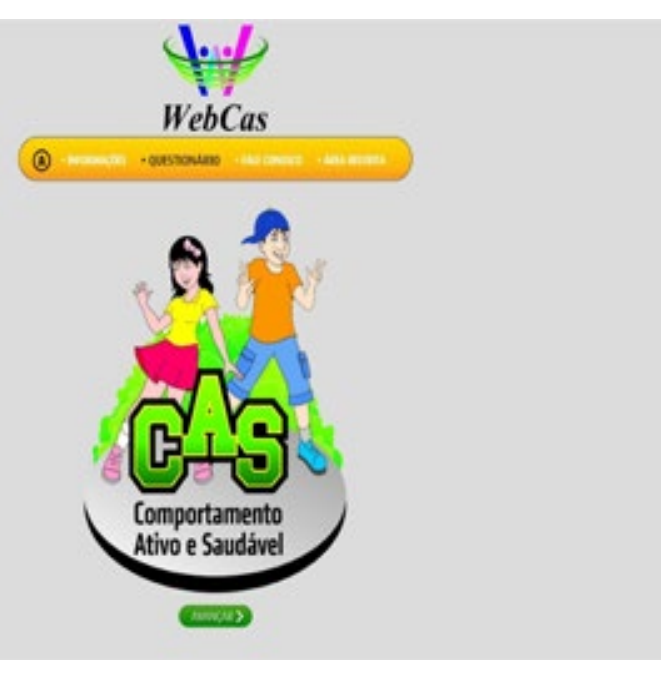

FIGURE 1- WebCas Electronic Questionnaire Home Screen

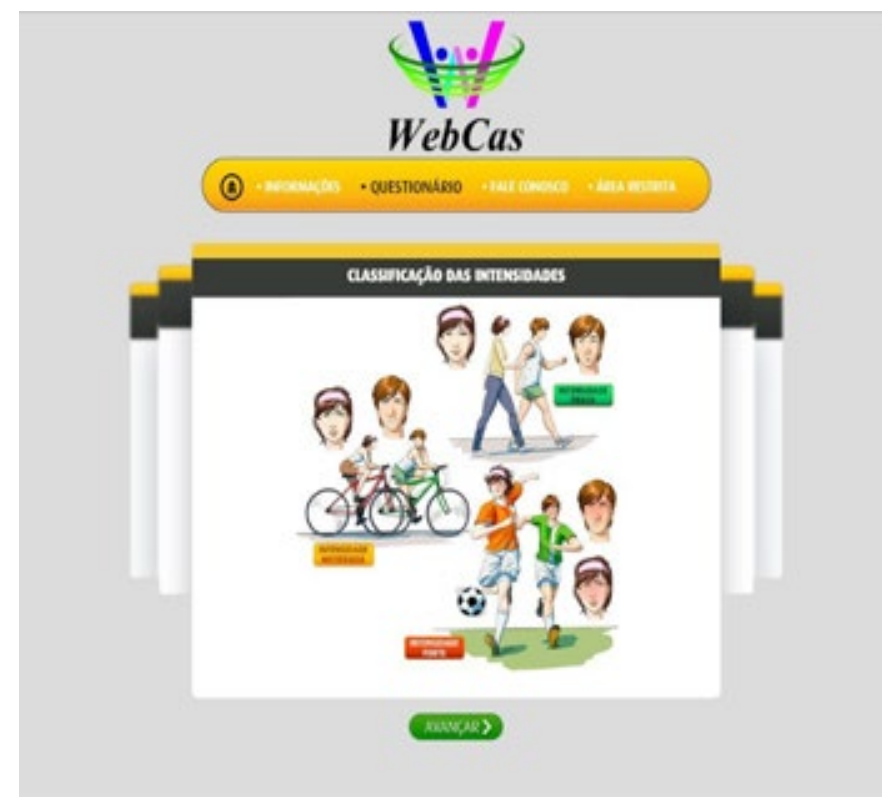

FIGURE 3 - WebCas activity intensity rating screen.

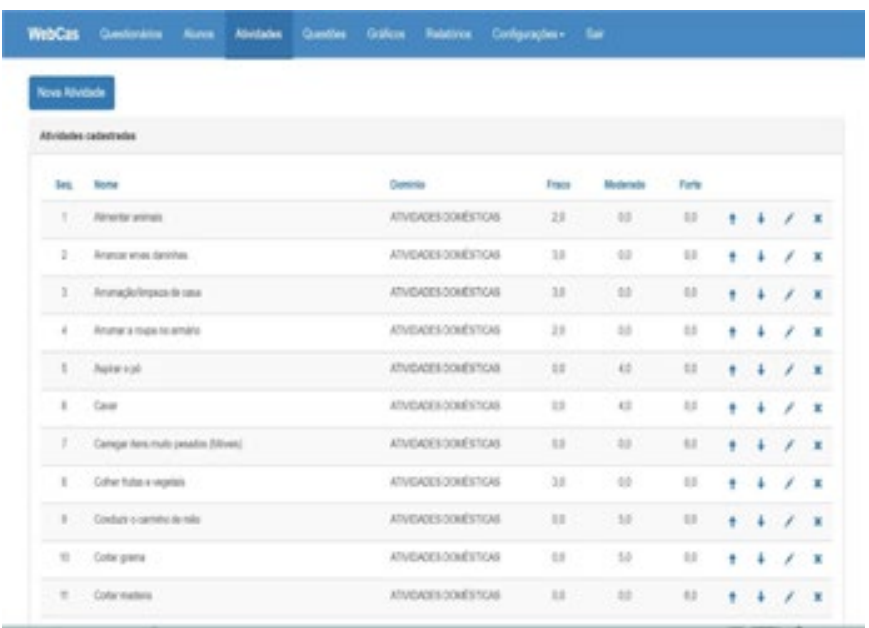

FIGURE 5 - Screen demonstrating the restricted area, activities, and their respective values of energy expenditure in Mets - WebCas.

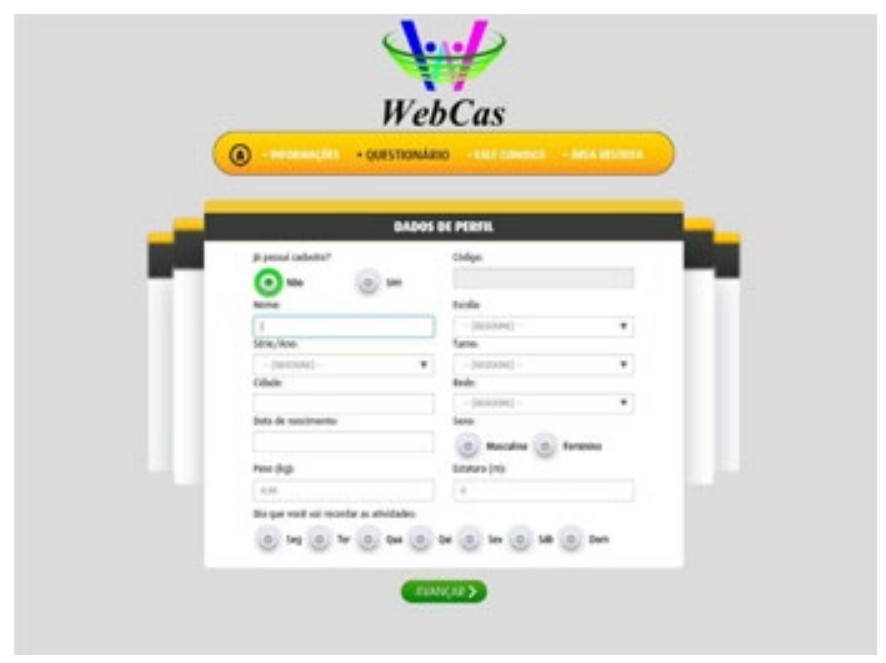

FIGURE 2 - WebCas Registration Screen

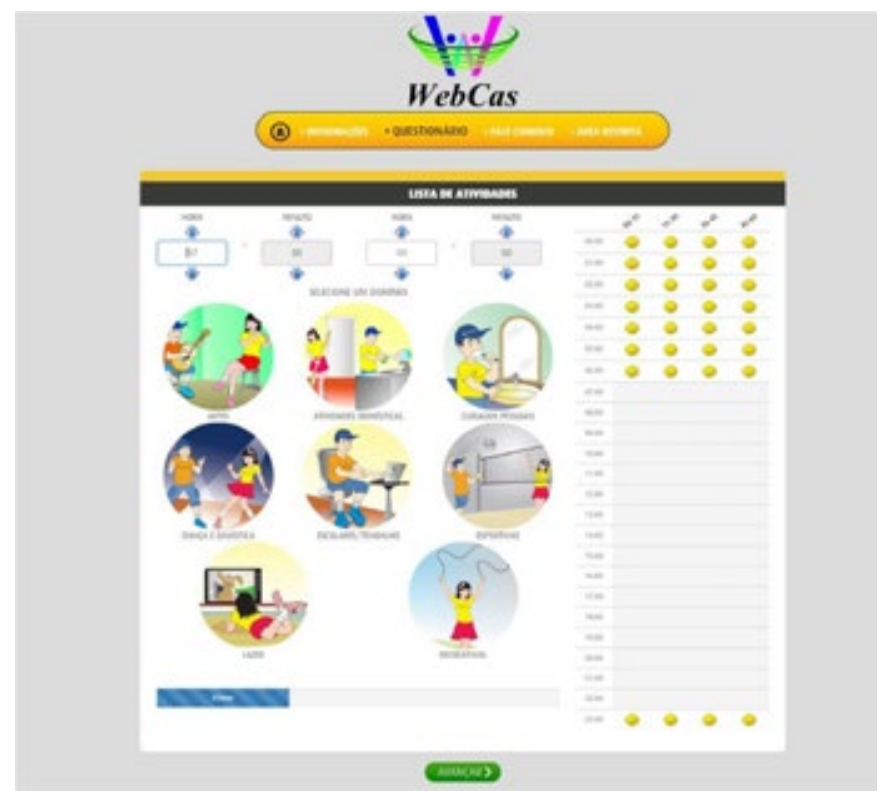

FIGURE 4 - The eight WebCas activity domains screen.

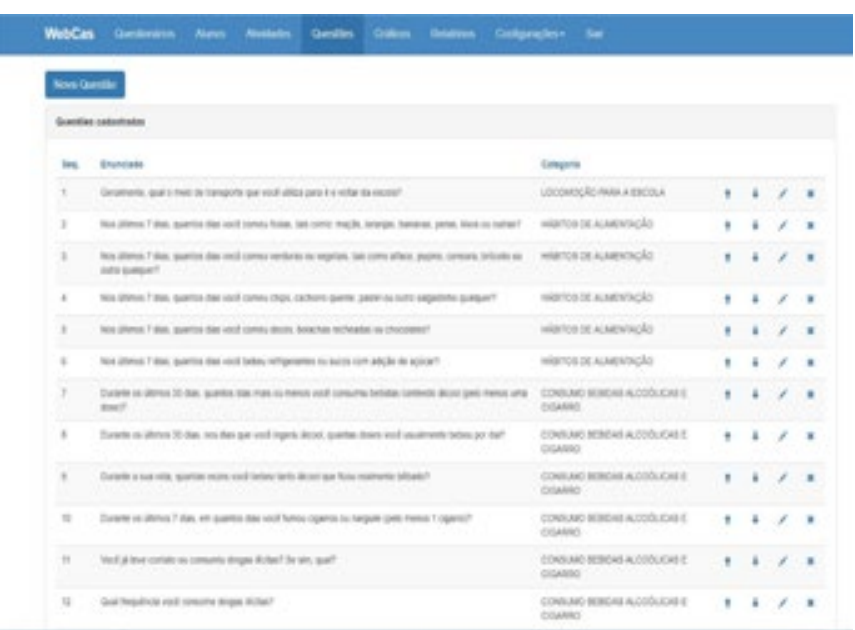

FIGURE 6 - Restricted area demo screen for WebCas questions 


\section{Discussion}

Recently, various tools based on information technology and the worldwide web are leveraging the Web and Mobile application development to assess behavioral aspects such as the practice of physical activity, eating frequency, sleeping hours, consumption of licit and illicit drugs. Corroborating the information above, we can mention electronic questionnaires, Webdafa ${ }^{6}$ and Whoqolweb ${ }^{13}$ designed to evaluate the main behaviors related to children's health (6 to 10 years) and the elderly's quality of life, respectively. They can be accessed at www.criancaativaesaudavel.com.br and http://www.whoqolweb.com.br, respectively.

Evidence indicates that electronic questionnaires can be more attractive to people because of their administration method ${ }^{14,15}$. In addition, electronic questionnaires have some advantages over printed instruments, such as immediate and direct access to the data entered, eliminating manual data entry and printing costs, greater accuracy, and faster data gathering ${ }^{10,16,17}$.

In a study by Bonn et al. ${ }^{18}$, the authors highlight the need to design and validate questionnaires specifically for use on the web-based on the increased use of computers by various people at various ages. Regarding the above, other authors have developed electronic instruments and advise the scientific community to use innovative tools with this format, as found in the electronic questionnaire ${ }^{19,20}$. Moreover, the web format of electronic questionnaires seems to be more attractive to people of all ages, especially when it comes to children ${ }^{6}$.

On one side, the WebCas questionnaire has features available in its restricted area allowing the inclusion of additional questions to its original format, a database allowing the individual's data to be stored in various stages of a study, providing comparative data in time series of the same individual and group. At the end of the data gathering process, the researcher can visualize dynamic graphs, fed by the respondent's information. Moreover, this instrument enables faster feedback on the variables analyzed, thus contributing to effective implementation and intervention of public policies of primary health care for children and adolescents ${ }^{6}$.

These factors may have direct implications for epidemiological studies at regional, state, and national levels, as they may increase the scope of the studies, adding accuracy in relation to the number of individuals researched and, consequently, the sample universe $\mathrm{e}^{6,12,19,21}$.

On the other side, web and mobile questionnaires may have some downsides regarding their use. Since problems such as failing to scroll to the end of the page, or being unable to correct a wrong answer, can generate invalid data ${ }^{22}$. In addition, the need to offer the respondent the possibility of setting up the web questionnaire or the Mobile application, as well as the need to access the instrument via the web, can become a barrier to its use in some regions of Brazil ${ }^{6,23}$.

\section{Conclusion}

The process of transposing the printed version to the electronic version of the WebCas questionnaire is one of the pioneering initiatives regarding the use of information technology resources to assist researchers in the collection, storage, and preliminary processing of data regarding health-related behaviors. The features presented by the WebCas questionnaire demonstrate that web-based instruments can have numerous advantages over traditional pen and paper models. Thus, this instrument is expected to contribute to the improvement of behavioral research involving adolescents from various regions of Brazil.

\section{References}

1. Lee I-M, Shiroma EJ, Lobelo F, Puska P, Blair SN, Katzmarzyk PT. Impact of Physical Inactivity on the World's Major NonCommunicable Diseases. Lancet. 2012;380(9838):219-29.

2. Wilmot EG, Edwardson CL, Achana FA, Davies MJ, Gorely T, Gray LJ, et al. Sedentary time in adults and the association with diabetes, cardiovascular disease, and death: Systematic review and meta-analysis. Diabetologia. 2012;55(11):2895-905.

3. Meneguci J, Santos DAT, Silva RB, Santos RG, Sasaki JE, Tribess $\mathrm{S}$, et al. Comportamento sedentário: conceito, implicações fisiológicas e os procedimentos de avaliação. Motricidade [Internet]. 2015;11(1):160-74. Available from: http://revistas.rcaap.pt/ motricidade/article/view/3178

4. Whittaker R, McRobbie H, Bullen C, Rodgers A, Gu Y. Mobile phone-based interventions for smoking cessation (Review). Cochrane Database Syst Rev. 2016;(11):1-24.

5. Lorenzetti J, Trindade L de L, Pires DEP de, Ramos FRS. Tecnologia, inovação tecnológica e saúde: uma reflexão necessária. Texto Context - Enferm [Internet]. 2012;21(2):432-9. Available from: http://www.scielo.br/scielo.php?script=sci_arttext\&pid=S0104-07072012000200023\&lng=pt\&tlng=pt

6. Legnani E, Rech C, Campos W. Instrumentos eletrónicos para avaliar atividade física em crianças : Uma revisão sistemática systematic review. 2013;9(4):90-9.

7. De Jesus GM, De Assis MAA, Kupek E, Dias LA. Avaliação da atividade física de escolares com um questionário via internet. Rev Bras Med do Esporte. 2016;22(4):261-6.

8. Vargas LM, Redkva PE, Junior AS, Pilatti LA, Gutierrez GL. Validação dos questionários eletrônicos IPAQ e EVF em estudantes universitários de Educação Física na modalidade à distância. Rev Bras Qual Vida. 2013;5:9-18.

9. Legnani RFDS. Elaboração, validação e aplicação de um questionário via web para avaliar os comportamentos relacionados à saúde em escolares. Curitiba. Tese [Doutorado em Educação Física] - Universidade Federal do Parana; 2015.

10. Schneider BC, Motta JVS, Muniz LC, Bielmann RM, Madruga SW, Orlandi SP et al. Design of a digital and self - reported food frequency questionnaire to estimate food consumption in adolescents and young adults : birth cohorts at Pelotas, Rio Grande do Sul, Brazil. Rev Bras Epidemiol. 2016;19(2):419-32.

11. Legnani RFS, Camargo E, Legnani E, Bacil E, Neto NAM, Campos W de. Students' and teachers' understanding of the WebCas questionnaire for assessing health-related behaviors. Rev Bras Atividade Física Saúde [Internet]. 2017;22(3):251-60. Available from: https:// periodicos.ufpel.edu.br/ojs2/index.php/RBAFS/article/view/9063

12. Apovian CM, Murphy MC, Cullum-Dugan D, Lin PH, Gilbert $\mathrm{KM}$, Coffman $\mathrm{G}$, et al. Validation of a web-based dietary 
questionnaire designed for the DASH (Dietary Approaches to Stop Hypertension) diet: The DASH Online Questionnaire. Public Health Nutr. 2010;13(5):615-22.

13. Casamali FFC. Concordância e reprodutibilidade da versão eletrônica dos questionários WHOQOL-BREF e WHOQOL-OLD. Dissertação [Mestrado em envelhecimento humano]- Universidade de Passo Fundo; 2018.

14. Lévesque L, Cargo M, Salsberg J. Development of the Physical Activity Interactive Recall ( PAIR ) for Aboriginal children. Int J Behav Nutr Phys Act. 2004;11:1-11.

15. McLure Sally A, Reilly John J, Crooks Sean SCD. Development and Evaluation of a Novel Computer-Based Tool for Assessing Physical Activity Levels in Schoolchildren. Hum Kinet Journals. 2009;21(4):506-19.

16. CA, Vereecken, M, Covents, C, Matthys, L, Maes. Young adolescents ' nutrition assessment on computer ( YANA-C ). Eur J Clin Nutr. 2005;59:658-67.

17. Gwaltney CJ, Shields AL, Shiffman S. Equivalence of Electronic and Paper-and-Pencil Administration of Patient-Reported Outcome Measures: A Meta-Analytic Review. Value Heal [Internet]. 2008;11(2):322-33. Available from: http://dx.doi. org/10.1111/j.1524-4733.2007.00231.x

18. Bonn SE, Lagerros YT, Christensen SE, Möller E, Wright A, Sjölander A, et al. Active-Q : Validation of the Web-Based Physical Activity Questionnaire Using Doubly Labeled Water Corresponding Author : J Med Internet Res. 2012;14(1):1-11.

19. Moore HJ, Ells LJ, Mclure SA, Crooks S, Cumbor D, Summerbell $\mathrm{CD}$, et al. The development and evaluation of a novel computer program to assess previous-day dietary and physical activity behaviours in school children: The Synchronised Nutrition and Activity Program TM ( SNAP TM ). Br J Nutr. 2008;99:1266-74.

20. Biltoft-jensen A, Hjorth MF, Trolle E, Christensen T, Brockhoff $\mathrm{PB}$, Andersen LF, et al. Comparison of estimated energy intake using Web-based Dietary Assessment Software with accelerometer-determined energy expenditure in children. Food Nutr Res. 2013;57:1-12.

21. Ridley K, Ainsworth BE, Olds TS. Development of a Compendium of Energy Expenditures for Youth. Int J Behav Nutr Phys Act. 2008;5(45):1-8.

22. Jamia EC. When to Use Web-based Surveys. J Am Med Informatics Assoc. 2000;7(4):426-30.

23. Costa, FF, Schmoelz, CP, Davies, VF, Di Pietro, PF, Kupek, E, Assis, MAA. Assessment of Diet and Physical Activity of Brazilian Schoolchildren : Usability Testing of a Web-Based Questionnaire Corresponding Author: JMIR Res Protoc. 2013;2(31):1-15.

\section{Corresponding author}

Rosimeide Francisco dos Santos Legnani

Campus Uvaranas - Av. General Carlos Cavalcanti, 4748 - CEP 84030-900 - Departamento de Educação Física - Bloco G , Fone: (42) 3220-3000 / 3220-3300, Ponta Grossa, Paraná

Email:legnanirosi@gmail.com

Editor: Romulo A Fernandes, UNESP/Presidente Prudente, SP, Brazil

Manuscript received on March 24, 2020

Manuscript accepted on June 15, 2020

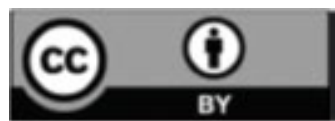

Motriz. The Journal of Physical Education. UNESP. Rio Claro, SP, Brazil - eISSN: 1980-6574 - under a license Creative Commons - Version 4.0 